\title{
Evaluation of The Swelling Ability And Water Binding Capacity Of Some Local Plant Consumed In Adamawa State, Nigeria.
}

\author{
N.M. Gaila ${ }^{1 *}$, M. Buba ${ }^{1}$ and A. Ahmed ${ }^{1}$ \\ ${ }^{1}$ Department of Science Laboratory Technology, Federal polytechnic Mubi, Adamawa State \\ *Corresponding Author: nmgaila@ gmail.com, +2348032462186 \\ Received 01 June 2020; accepted 27 June 2020, published online 28 August 2020
}

\begin{abstract}
The functional properties are the intrinsic physicochemical characteristics which affect the behavior of ingredient in food systems during processing, manufacturing, storage and preparation etc. Such functional properties include water and oil binding, emulsification capacities, swelling ability and viscosity. This work is aimed at evaluating the swelling Ability and water binding capacities of Spinous Amarantus (alayahon daji) (AA) Senna accedentalis (tasba) (TB), Phyllantus niruri (mace mai goyo) (MC), Hibiscus sabdrariffa (yakuwan daji) (YD) and Leptadenia hastate (yadiya) (YE) which are commonly consumed in our localities with little or no knowledge about their nutritional properties. AOAC method of analysis as outlined by Adabowale was adopted for the analysis with little modifications. All the samples analyzed showed significant water swelling ability with AA and YD showing the highest values of $1.5 \pm 0.06 \mathrm{v} / \mathrm{g}$ while TB shows the lowest value of $0.5 \pm 0.05 \mathrm{v} / \mathrm{g}$. There was a significant difference $(\mathrm{p}<0.05)$ in the WBC values $(\%)$ obtained for the different plants analyzed. The results revealed that crude AA has the highest value of $12.48 \pm 0.82$ and YD has the lowest value of 5.50 \pm 0.09 . Insoluble dietary fiber (IDF) was also extracted from the samples and evaluated for water binding capacity. The Insoluble dietary fibre (IDF) showed WBC values. The highest values $1.54 \pm 0.08 \mathrm{~g} / \mathrm{g}$ and lowest $0.94 \pm 0.00 \mathrm{~g} / \mathrm{g}$ were obtained $\mathrm{MC}$ and YE respectively. All the crude samples showed significant water binding capacity (WBC) than their respective insoluble dietary fiber (IDF). This is as a result of the structural and chemical composition of the crude samples. However, the research has revealed that both the crude and the IDF samples analyzed has therapeutic potentials.
\end{abstract}

Keywords: Plant samples, Dietary Fibre, water-binding and swelling index.

\section{INTRODUCTION}

Many herbal drugs are of specific for the therapeutic or pharmaceutical utility because of their swelling properties - especially gums and drugs those are containing an appreciable amount of constituents like mucilage, pectin or hemicelluloses. The swelling index is defined as the volume in ml taken up by the swelling of $1 \mathrm{~g}$ of herbal material under specified conditions. Hydration properties of the feed are very important for effective digestion to occur in the animal and can be characterized by water binding capacity (WBC) [1]. WBC is the quality of water that remains bounded to the hydrated fibers following the application of an external force (pressure or centrifugation), is an important property of dietary fiber (DF) from both physiological and technological points of views [2]. Dietary fiber has distinct physicochemical properties. Most semi - solid foods, fiber and fat are a combination of gel matrices which are hydrated or collapsed with micro structural elements, globules, solutions or encapsulating walls. Fresh fruit and vegetables are cellular materials. [3,4] which reduces the incidence of CNS disorders [5]. The cells of cooked potatoes and legumes are gels filled with gelatinized starch granules. The cellular structures of fruits and vegetables are foams with a closed cell geometry filled with a gel, surrounded by cell walls which are composites with an amorphous matrix strengthened by complex carbohydrate fibers. Particle size and interfacial interactions with adjacent matrices affect the mechanical properties of food composites.

Food polymers may be soluble in and/or plasticized by water. Water is the most important plasticizer, particularly in biological systems thereby changing mechanical properties. The variables include chemical structure, polymer concentration, molecular weight, degree of chain branching, the extent of ionization (for electrolytes), solution $\mathrm{pH}$, ionic strength and temperature. Cross-linking of different polymers, protein and polysaccharides, either through chemical covalent bonds or cross-links through molecular entanglement or hydrogen or ionic bond cross - linking. Cooking and chewing of 
food alters these physicochemical properties and hence absorption and movement through the stomach and along the intestine[6,7].

Aim: The main objective of present experiment is to measure the swelling factor of the Plant samples, to extract insoluble dietary fiber from the studied samples and evaluate the water binding capacity of both the crude and the insoluble dietary fiber of the samples analyzed.

\section{Material and Methods Sample Collection and Preparation}

The samples of Spinous Amarantus (alayahon daji) (AA) Senna accedentalis (tasba) (TB), Phyllantus niruri (mace mai goyo) (MC), Hibiscus sabdrariffa (yakuwan daji) (YD) and Leptadenia hastate (yadiya) (YE) were collected from Madagali, Numan and Yola agricultural farms in Adamawa packaged, coded and taxonomically authenticated by a Botanist $(\mathrm{Mr}$ Bristone Basiri) in the Department of Biological sciences, Modibbo Adama University of Technology, Yola. The samples were sorted-out to remove unwanted materials, and then dried under room temperature for $72 \mathrm{~h}[8,9]$. They were ground to powdered form using mortar and pestle and sieved with laboratory test sieves (BS410/1986) to obtain the desired homogenous particle size $(30 \mathrm{~mm})$. The experiment was carried out at national institute for pharmaceutical research and development (NIPRD) Abuja.

\section{Determination of swelling index}

A $2.0 \mathrm{~g}$ portion of sample was weighed a calibrated cylinder $(2 \mathrm{~cm}$ in diameter) and hydrated with $30 \mathrm{~cm}^{3}$ of distilled water at room temperature (approximately $25^{\circ} \mathrm{C}$ ) for $24 \mathrm{~h}$. The change in volume was and recorded and expressed as the volume/g of the original sample (dry weight) [10].

\section{Water binding capacity (WBC) determination}

The insoluble dietary fiber (IDF) was extracted using enzymatic-gravimetric method as described by $[11,12]$. A $0.5 \mathrm{~g}$ portion of the samples (crude and IDF) was weighed into clean pre- weighed dried centrifuge tube and mixed with $7.5 \mathrm{~mL}$ distilled water. After $24 \mathrm{~h}$ of equilibration at room temperature (approximately $25{ }^{\circ} \mathrm{C}$ ), the suspension was centrifuged at $4,200 \mathrm{rpm}$ for 15 min. Subsequently the supernatant was decanted the tube with the sediment was weighed after removal of the adhering drops of water [13]. The water binding capacity (WBC) was calculated using.

$$
\underset{g}{\mathrm{WBC}(\boldsymbol{g})}=\frac{\mathrm{W}_{2}-\mathrm{W}_{1}}{\text { Weight of Sample }}
$$

where $\mathrm{W}_{1}$ is the weight of empty centrifuge tube and $\mathrm{W}_{2}$ is the weight of centrifuge tube and sediment after removal of water.

\section{RESULTS AND DISCUSSION}

The water binding capacity of the crude and insoluble dietary fiber values is compared as shown in table I while the water swelling ability and the water binding capacity of the crude samples is presented in tables II below

TABLE I: Water Binding capacity (WBC) of the Crude Sample and Insoluble Dietary fiber (IDF) Samples

\begin{tabular}{ccc}
\hline Sample code & \multicolumn{2}{c}{ WBC(g/g) } \\
\hline & Crude & IDF \\
\hline AA & $12.48 \pm 0.82$ & $1.26 \pm 0.09$ \\
TB & $10.75 \pm 0.63$ & $1.38 \pm 0.03$ \\
MC & $6.19 \pm 0.15$ & $1.54 \pm 0.08$ \\
YD & $5.50 \pm 0.09$ & $1.40 \pm 0.01$ \\
YE & $8.69 \pm 0.10$ & $0.94 \pm 0.00$ \\
\hline
\end{tabular}

TABLE II: Water Binding capacity (WBC) and Water Swelling Ability of the Crude Samples

\begin{tabular}{clr}
\hline Sample Code & WBC $(\mathrm{g} / \mathrm{g})$ & WSA(v/g) \\
\hline AA & $12.48 \pm 0.82$ & $1.5 \pm 0.02$ \\
TB & $10.75 \pm 0.63$ & $0.5 \pm 0.05$ \\
MC & $6.19 \pm 0.15$ & $1.0 \pm 0.05$ \\
YD & $5.50 \pm 0.09$ & $1.5 \pm 0.09$ \\
YE & $8.69 \pm 0.10$ & $1.0 \pm 0.07$ \\
\hline
\end{tabular}

All the samples analyzed showed significant water binding capacity and swelling ability as shown in fig 1 . The greatest changes in the water swelling ability of the samples analyzed was observed in AA and YD showing the value of $1.5 \pm 0.06 \mathrm{v} / \mathrm{g}$ while the lowest value was observed in TB $0.5 \pm 0.05 \mathrm{v} / \mathrm{g}$. The low swelling index value obtained could be attributed to low content of starch in the plant samples analyzed. 
The low the starch content the lower the swelling power. This supports the finding of [14] .

The water binding capacity of the YD and AA ranged from $5.50 \pm 0.09$ to $12.48 \pm 0.82 \mathrm{~g} / \mathrm{g}$ respectively. The highest WBC were obtained in the results can be explained by the proximity of the isoelectric point in the case of the proteins, and regarding the polysaccharides.

Foods with high water binding may have more hydrophilic constituents like polysaccharides and interacts with water similar observation was reported by $[15,16]$. The majority of polysaccharides contain glycosyl units that have three hydroxyl groups in their structure. Each of these groups has the possibility to form hydrogen bonds with one or more molecules of water. In aqueous systems, particles of polysaccharide molecules can capture water, swell, and generally undergo partial or complete dissolution. The water binds to the molecules of the polysaccharides by hydrogen bonds. In general, the polysaccharides become more soluble depending on the degree of irregularity of the molecular chains, i.e. the greater the difficulty for the molecules to bind, the higher the hydration $[17,18]$. Also reported that low WBC in some foods is due to less polar amino acids in the food samples.

The water binding capacity and the swelling ability of the crude samples presented in Fig 1

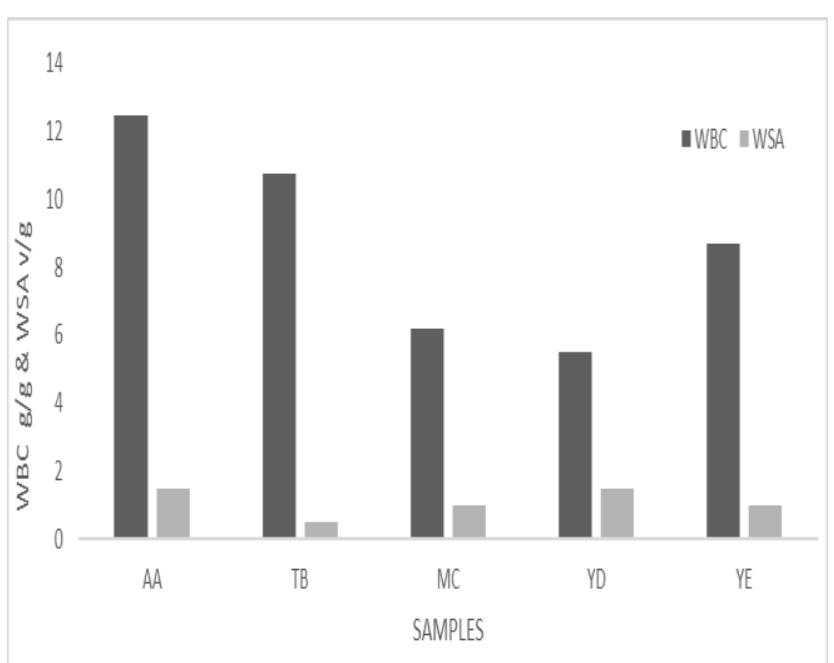

Figure 1. Water Binding Capacity \& Water Swelling Ability of the crude plants samples.

Key: $\mathrm{WBC}=$ Water Binding Capacity, Water swelling ability (WSA), Spinous amarantthus (AA) Senna accedentalis (TB), Phyllanthus niruri $(M C)$, Hisbiscus-sabdariff $(Y D)$, Lebtadenia hastata (YE).
The water binding capacity (WBC) of the crude samples and their extracted insoluble dietary fibers (IDF) was studied and result presented in Fig 2.

Figure 2. Water Binding Capacity of Crude Samples and their Extracted Insoluble Dietary Fiber IDF)

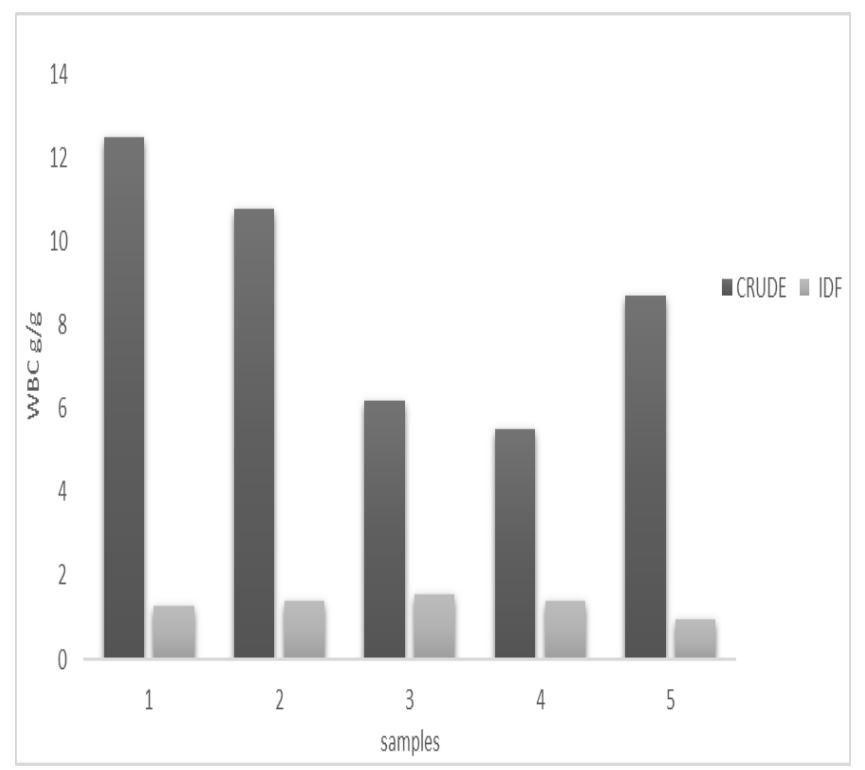

Key: IDF = Insoluble dietary fiber, Spinous amarantthus (AA) Senna accedentalis (TB), Phyllanthus niruri (MC), Hisbiscussabdariff $(Y D)$, Lebtadenia hastata $(Y E)$

It can be observed in Fig. 2. That all the studied crude samples showed significantly higher WBC than their respective IDF. This attributes to the difference in the structural characteristics and chemical composition of the crude and IDF samples as a result of the fiber extraction process. During fiber extraction, some of the chemical composition (molecular components) of the crude samples are removed in the form of SDF and thus, leaving the IDF with less molecular components compared to the crude sample [19]. Hence, the crude sample has molecular components with affinity for water while the IDF has little or none of these molecular components. However, some components of IDF such as hemicelluloses and lignin have water affinity [20] . This attributes to the significant WBC of IDF samples analyzed. This suggests that chemical composition as well as structural properties play important role in the kinetics of water absorption.

\section{CONCLUSION}

The plants analyzed are consumed in our localities 
with little or no knowledge about their nutritional properties. This work helped us to determine the swelling and water binding ability of the plants. The fiber extraction process caused the destruction of chemical composition of the samples. However, the research has revealed that both the crude and the IDF samples analyzed has therapeutic potentials. The samples analyzed are good source of dietary fiber with body detoxification potentials.

\section{Recommendation}

The research has contributed immensely to knowledge by being a reference and teaching material for those interested in similar research and has added both nutritional and economic value to the local plants analyzed. It will also enrich the chemical data bank which will contribute to the overall wellbeing of people in the rural areas at a cheaper cost. The result obtained showed that the crude samples investigated and their extracted dietary fibers have some therapeutic potential. Thus, the plants can be alternative supplements for dietary fiber, starch and polysaccharides.

\section{REFERENCES}

1. Ngoc TTB, Len NT, Lindberg JE. Chemical Characterization and Water Holding Capacity of Fibre-rich Feedstuffs Used for Pigs in Vietnam. Asian-Aust $J$ Anim Sci. 2012;25(6):861-868. doi:10.5713/ajas.2011.11294

2. Tian Y, Wang K, Zhuang Z, Pan S, Huang $X$. Comparative Analysis of Dietary Fibre Extract Isolated from Citrus Juice Byproducts using Water Extraction, Fermentation and Enzymatic Treatment Methods. Adv J Food Sci Technol. 2014;6(9):1058-1066. doi:10.19026/ajfst.6.160

3. Hermanasson AM. Gel Structure of Food Biopolymers in Food Structure, Its Creation and Evaluation. 1988:25-40.

4. Stewart GF, Rockland LB. Water Activity: Influences on Food Quality. Academic Press. 1981:950.

5. Houghton P. Use of Medicinal Plants in CNS Disorders in Yanni Z. and $U$. Bachrach (Eds.). Vol 4.; 2007.

6. Leifert WR, Abeywardena MY. Grape Seed and Red wine Polyphenol Extracts inhibit Cellular Cholesterol Uptake, Cell Proliferation, and 5-lipoxygenase Activity.
Nutr Res. 2008;28(12):842-850. doi:10.1016/j.nutres.2008.09.001

7. Kaushal P, Kumar V, Sharma HK. Comparative Study of Physicochemical, Functional, Antinutritional and Pasting Properties of taro (Colocasia esculenta), Rice (Oryza sativa) Fl our, Pigeonpea (Cajanus cajan) $\mathrm{Fl}$ our and their Blends. LWT - Food Sci Technol. 2012;48(1):5968. doi:10.1016/j.lwt.2012.02.028

8. Li BW, Andrews KW, Pehrsson PR. Individual Sugars, Soluble, and Insoluble Dietary Fiber Contents of 70 High Consumption Foods. J Food Compos Anal. 2002; 15:715-723.

doi:10.1006/jfca.2002.1096

9. Lawal OS, Adebowale KO. Effect of Acetylation and Succinylation on Solubility Profile, Water Absorption Capacity, Oil Absorption Capacity and Emulsifying Properties of Mucuna Bean (Mucuna Pruriens) Protein Concentrate. Vol 48.; 2004. doi:10.1002/food.200300384

10. AOAC. AOAC: Official Methods of Analysis Association of Official Analytical Chemists 15th Edition, Volume 1. 1990;1:1-162.

11. Nami G, Jeffreytsware B, Chinedu OJ, Tarfa F. Extraction of Dietry Fibre from Selected Food Plants Grown in Adamawa and Gombe States North - Eastern Nigeria. J Chem Soc Niger. 2018;43(3):583-588.

12. Lee CS, Prosky L, Jonathan DVW. Determination of Total, Soluble, and Insoluble Dietary Fiber in FoodsEnzymatic-Gravimetric Method, MESTRIS Buffer: Collaborative Study. J AOAC Int. 1992;75(3):395-416.

13. Adebowale AA, Adegoke MT, Sanni SA, Adegunwa MO, Fetuga GO. Functional Properties and Biscuit Making Potentials of Sorghum-wheat Flour Composite. Am J Food Technol. 2012;7(6):372-379.

14. Anderson JW, Richard HDJ, Ferreri S, Knudtson M, Koraym A, Waters V. Health Benefits of Dietary Fiber. Nutr Rev. 2009;67(4):188-205. doi:10.1111/j.17534887.2009.00189.x

15. Eastwood, Martin A, Morris, Edwin R. Physical Properties of Dietary Fiber that Influence Physiological Function: A Model for Polymers along the Gastrointestinal Tract. Am J Clin Nutr. 1992;55(2):436-442. doi:10.1093/ajen/55.2.436 
16. Waterschoot J. Unraveling the Factors Influencing the Interactions between Starches Inblends thereof upon Swelling, Gelatinisation and Gelation. https://www.biw.kuleuven.be.

17. Damoradan PK., Fennema O. Quimica de Alimentos de Fennema. Porto Alegre: Artmed; 2010.

18. Kuntz ID. Hydration of Macromolecules Hydration of Polypeptides. J Am Chem Soc. 1971;93(2):514-516.

19. American Association of Cereal Chemists. The Definition of Dietary Fiber: Report of the Dietary Fiber Definition Committee to the Board of Directors of the American Association of Cereal Chemists. Vol 46.; 2001.

20. Holloway WD, Greig RI. Water Holding Capacity of Hemicelluloses from Fruits, Vegetables and Wheat Bran. J Food Sci. 1984;49:1632-1633. 